\title{
Sensing and Autonomy for Riverine Vessels
}

\author{
Daniel J. Stilwell \\ Bradley Department of Electrical and Computer Engineering \\ Virginia Tech \\ 340 Whittemore Hall \\ Blacksburg, VA 24061 \\ Phone: (540) 231-3204 Fax: (540) 231-3362 Email: stilwell@vt.edu \\ Craig A. Woolsey \\ Aerospace and Ocean Engineering Department \\ Virginia Tech \\ 215 Randolph Hall \\ Blacksburg, VA 24061 \\ Phone: (540) 231-8117 Fax: (540) 231-9632 Email: cwoolsey@vt.edu \\ Award Numbers: N00014-11-10532 \\ http://www.unmanned.vt.edu
}

\section{LONG-TERM GOALS}

The principal goal of this project is to develop the technology and algorithms that will enable an unmanned surface vehicle (USV) to operate fast and autonomously in unknown riverine environments, including tropical rivers. Robust autonomy requires that the USV senses the surface and subsurface environments, discriminates waterways that are navigable from those that are not, identifies stationary and moving obstacles, including other vessels, and then optimally plans and re-plan a route in realtime. Since speed is a vessel's principal defense, all of these tasks must be done as efficiently as possible to ensure successful operation at the greatest possible speed.

This project is tightly coordinated with collaborators at the Naval Postgraduate School (NPS) whose work is conducted under a related project. All of the work reported herein was jointly developed with our NPS collaborators.

\section{OBJECTIVES}

Specific objectives for VT and NPS during 2012 reported herein are

1. Field trails of the Sensing and Autonomy Package on the Pearl River

2. Development of the Helmsman Assist System and experimental trials

3. Development of control architecture for sternward motion

4. Field trials of USV maneuvers that include backward motion 


\section{Report Documentation Page}

Form Approved

OMB No. 0704-0188

Public reporting burden for the collection of information is estimated to average 1 hour per response, including the time for reviewing instructions, searching existing data sources, gathering and maintaining the data needed, and completing and reviewing the collection of information. Send comments regarding this burden estimate or any other aspect of this collection of information,

including suggestions for reducing this burden, to Washington Headquarters Services, Directorate for Information Operations and Reports, 1215 Jefferson Davis Highway, Suite 1204, Arlington

VA 22202-4302. Respondents should be aware that notwithstanding any other provision of law, no person shall be subject to a penalty for failing to comply with a collection of information if it

does not display a currently valid OMB control number.

\begin{tabular}{|c|c|c|}
\hline $\begin{array}{l}\text { 1. REPORT DATE } \\
\mathbf{2 0 1 2}\end{array}$ & $\begin{array}{l}\text { 2. REPORT TYPE } \\
\text { N/A }\end{array}$ & $\begin{array}{l}\text { 3. DATES COVERED } \\
\text { - }\end{array}$ \\
\hline \multirow{3}{*}{\multicolumn{2}{|c|}{$\begin{array}{l}\text { 4. TITLE AND SUBTITLE } \\
\text { Sensing and Autonomy for Riverine Vessels }\end{array}$}} & 5a. CONTRACT NUMBER \\
\hline & & 5b. GRANT NUMBER \\
\hline & & 5c. PROGRAM ELEMENT NUMBER \\
\hline \multirow{3}{*}{\multicolumn{2}{|c|}{ 6. AUTHOR(S) }} & 5d. PROJECT NUMBER \\
\hline & & 5e. TASK NUMBER \\
\hline & & 5f. WORK UNIT NUMBER \\
\hline \multicolumn{2}{|c|}{$\begin{array}{l}\text { 7. PERFORMING ORGANIZATION NAME(S) AND ADDRESS(ES) } \\
\text { Bradley Department of Electrical and Computer Engineering Virginia } \\
\text { Tech } 340 \text { Whittemore Hall Blacksburg, VA } 24061\end{array}$} & $\begin{array}{l}\text { 8. PERFORMING ORGANIZATION } \\
\text { REPORT NUMBER }\end{array}$ \\
\hline \multirow{2}{*}{\multicolumn{2}{|c|}{ 9. SPONSORING/MONITORING AGENCY NAME(S) AND ADDRESS(ES) }} & 10. SPONSOR/MONITOR'S ACRONYM(S) \\
\hline & & $\begin{array}{l}\text { 11. SPONSOR/MONITOR'S REPORT } \\
\text { NUMBER(S) }\end{array}$ \\
\hline
\end{tabular}

12. DISTRIBUTION/AVAILABILITY STATEMENT

Approved for public release, distribution unlimited

13. SUPPLEMENTARY NOTES

The original document contains color images.

14. ABSTRACT

15. SUBJECT TERMS

16. SECURITY CLASSIFICATION OF:

a. REPORT

unclassified b. ABSTRACT

unclassified
17. LIMITATION OF ABSTRACT

SAR
18. NUMBER

OF PAGES

7 19a. NAME OF RESPONSIBLE PERSON unclassified 


\section{APPROACH}

We seek to develop a sensing and autonomy package that can be deployed on a variety of small shallow-draft vessels. Thus our activities are focused on the development of sensing strategies, guidance and control algorithms, rather than on the development of a specific USV platform. Our goal is to operate quickly in large areas for which existing maps are inaccurate. To do so, we must address the following

1. Guidance: Guidance algorithms must be suitable for extremely large and poorly mapped riverine environments. Furthermore, they must meet real-time computational contraints.

2. Dynamics and control: Fundamental principles for control of shallow-draft riverine vessels are sought. The challenge being development of a control architecture that is suitable for the entire operating envelope of a USV, including backward motion.

3. Vessel integration: Because we seek to deploy our sensing and autonomy package on any riverine USV, we are developing a hardware mounting systems for our sensors. Our biggest effort has been directed toward development of a new generalized sonar mount.

We are also developing the Helmsman Assist System as a first step toward integrating autonomy into riverine vessels. The Helmsman Assist System provides a display with real-time map and routeguidance from the Sensing and Autonomy Package. It enables manned vessels to operate much faster than would otherwise be possible in all weather and in unfamiliar areas where unknown submerged hazards may exist.

\section{WORK COMPLETED}

\section{Field trials on the Pearl River}

During January 2012, the Sensing and Autonomy Package was successfully utilized for field trials on the Pearl River. Using the Sensing and Autonomy Package, the VT USV traveled the route shown in Figure 1. The USV traveled $6.3 \mathrm{~km}$ downriver, and then returned $6.3 \mathrm{~km}$ upriver. The USV used a laser line-scanner and a forward looking sonar to create a map of the river in real-time, and then continuously computed short-range dynamically feasible trajectories and long-range route plans. A generalized sonar mount was used to integrate the NPS sonar with the VT USV. All sonar signal processing algorithms were developed by NPS researchers.

The USV began the mission with a prior map created from a USGS map of the area. A surprising number of river features did not appear in the USGS map, but all were identified and avoided in realtime by the USV. Examples of discrepancies between the USGS map and the true environment are shown in Figure 3. They include bridge supports for the I-10 highway bridge, an island, and shifted shorelines. 


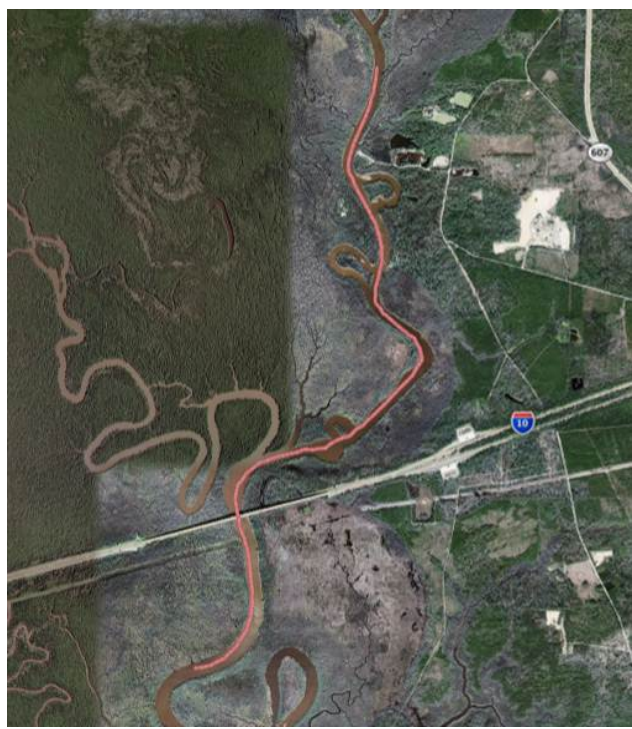

Figure 1. Path of riverine $U S V$ along Pearl River.

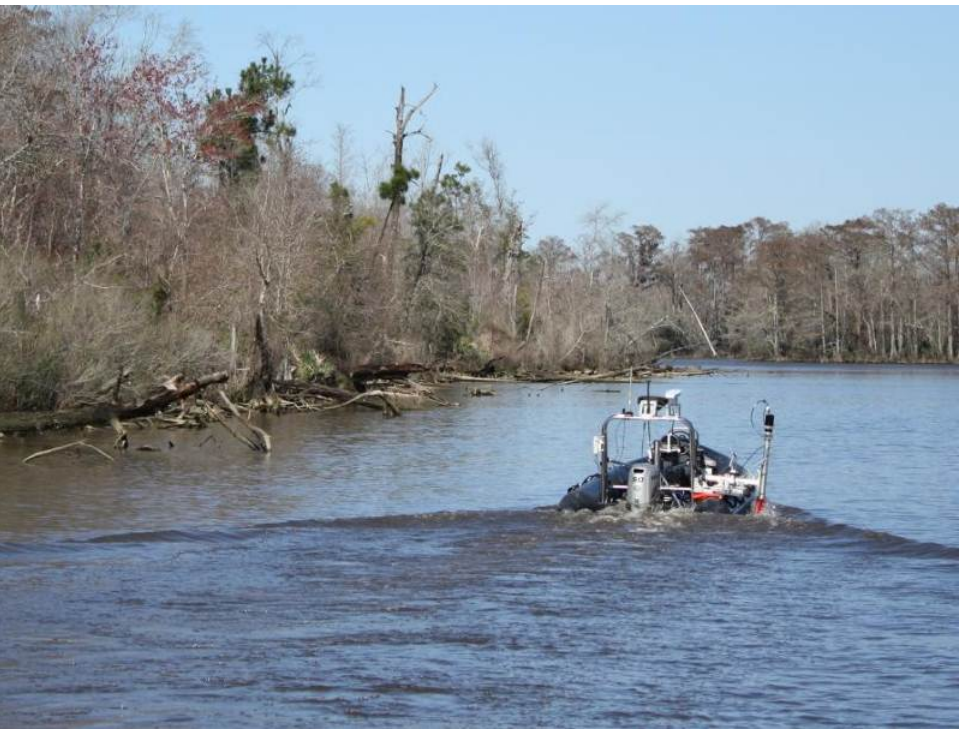

Figure 2. VT USV with Sensing and Autonomy Package.

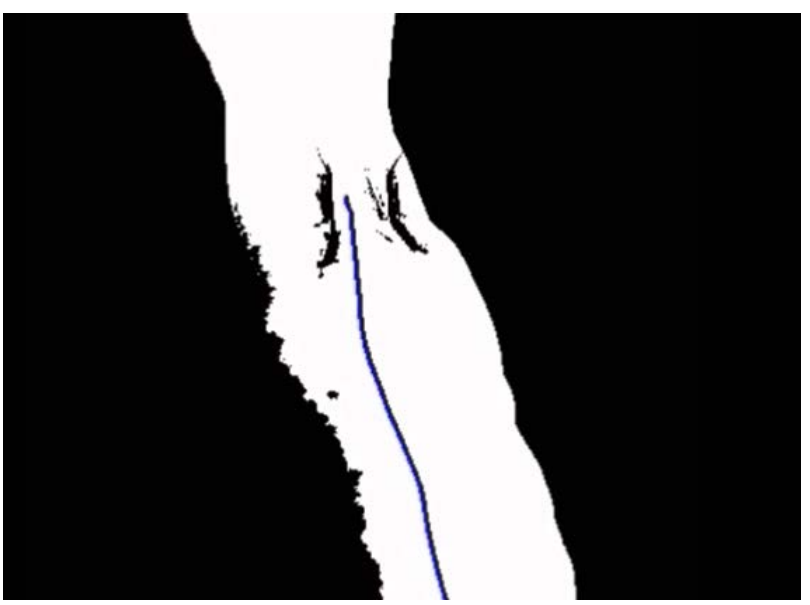

(a)
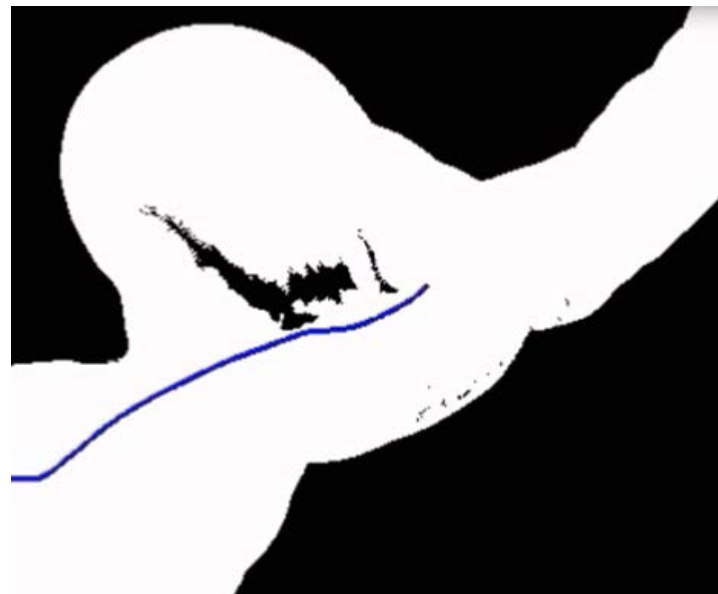

(b)

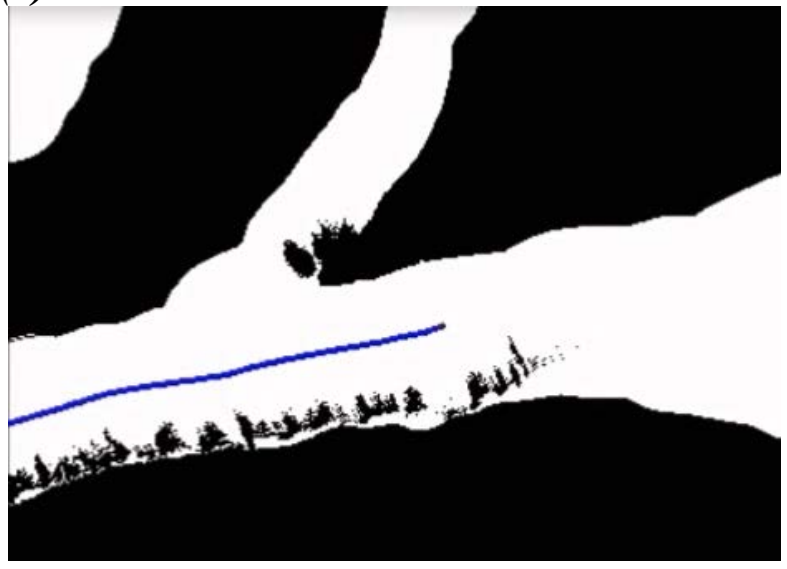

(c)

Figure 3. Map created by USV showing (a) I10 bridge support, (b) Island that does not appear in prior map, and (c) shifted shoreline. 


\section{Development of the Helmsman Assist System and experimental trials}

The Helmsman Assist System provides a real-time map and route guidance to the helmsman. It uses all components of the Sensing and Autonomy Package except for the autopilot. During FY12, VT and NPS completed initial development of the Helmsman Assist System and worked with NSWG4 operators to experimentally deploy the system on a SOC-R. We developed,

- A generalized sonar mount so that a forward-looking sonar could be deployed on most riverine vessels, including the SOC-R. The sonar mount, shown in Figure 3, is electronically deploys, retracts, and pans a dual sonar head. The same sonar mount was used to integrate the NPS sonar with the VT USV.

- An electronics enclosure that packages all computing and interface electronics for the laser linescanner, the sonar and sonar mount, a satellite compass, an AHRS, and an LCD display.

- A laser line-scanner mounting system for the SOC-R mast.

During Sept 2012, NPS and VT researchers integrated the Helmsman Assist System on a SOC-R and worked with NSWG4 personnel to experimentally deploy the system. Boat operators offered positive feedback after using the system and experessed a desire for additional development. Specific suggestions for further development were provided in a trip report that was prepared for ONR.
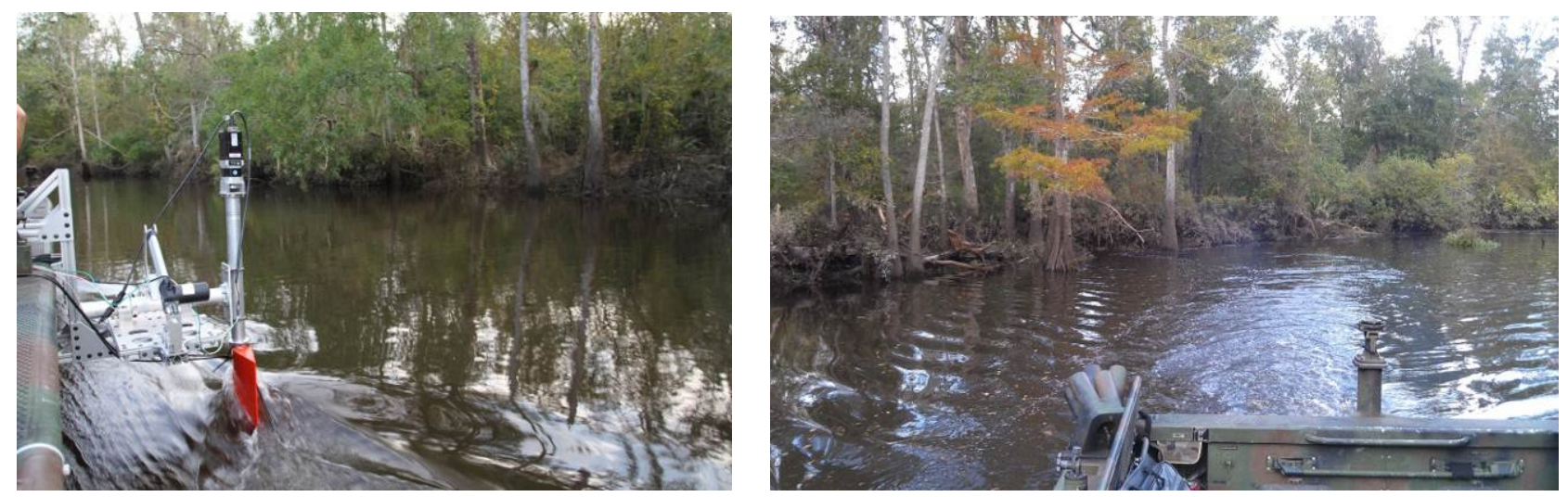

Figure 4. (left) Generalized sonar mount, (right) view of Pearl River from stern of SOC-R.

\section{Development of a control architecture that encompasses backward motion}

Having developed a method for obtaining a USV dynamic model from experimental data, we next developed two trajectory tracking control laws, implemented them on the VT USV, and compared their performance in field experiments. In the first approach, a cascade of proportional-derivative (PD) compensators accepts a desired speed and heading as reference inputs and computes a correction based on the cross track and along track error. In the second approach, a nonlinear "backstepping" controller was developed. (Backstepping is a Lyapunov-based control design method that is applicable to integrator cascade systems, such as mechanical systems where input forces "cascade" through the dynamic equations down to the kinematics.) 
Experimental comparisons of the two trajectory tracking control laws, illustrated in Figure 5, showed that the backstepping control law is much more effective at attaining and maintaining a commanded trajectory. The same backstepping control architecture was successfully applied to the case of backward motion, and the resulting control system provided excellent trajectory tracking during field trials. An illustration of trajectory tracking during backward motion is shown in Figure 6.
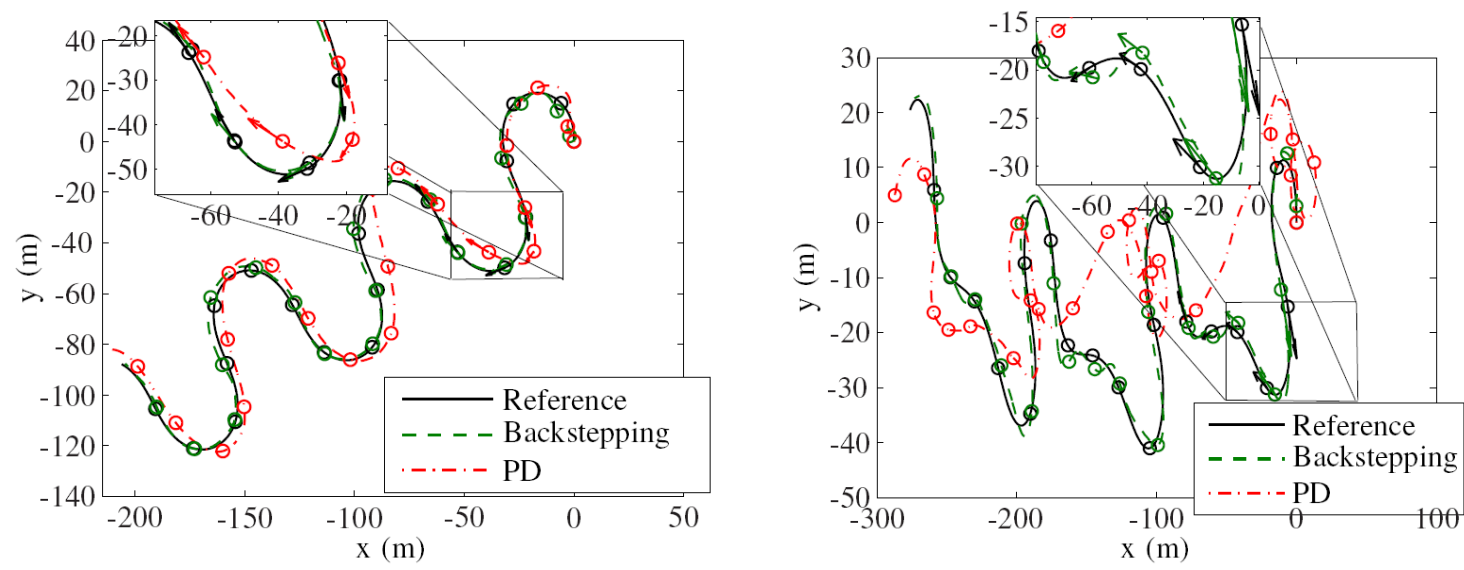

Figure 5. Experimental data illustrating the two approaches to trajectory tracking, where the reference trajectory is generated using a sinusoidally varying rudder angle and constant (left) or sinusoidally varying throttle (right). Note the especially poor performance of the PD cascade when the reference speed varies (right).

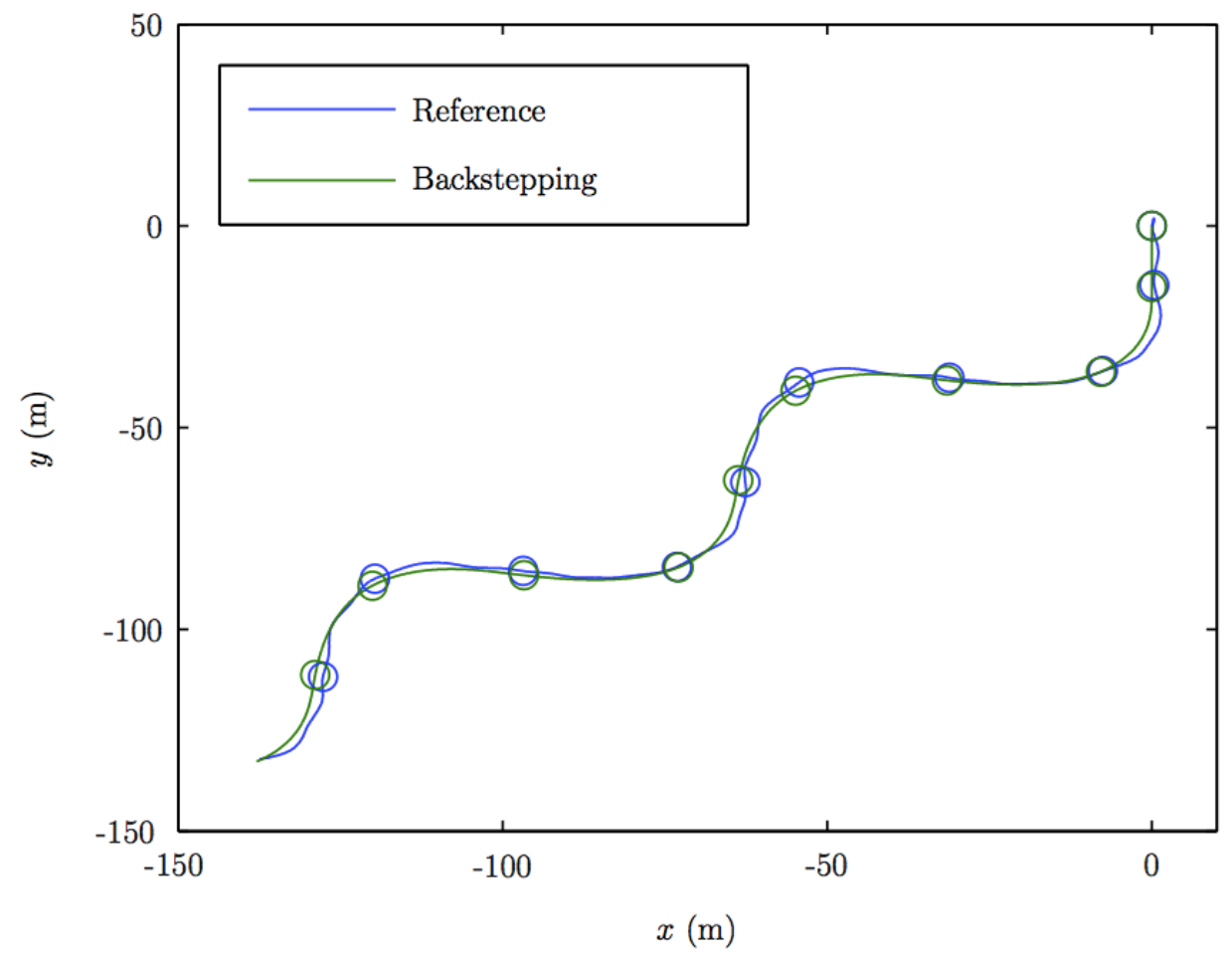

Figure 6. Experimental data illustrating the backstepping approach for trajectory tracking during backward motion. 


\section{Field trials of USV maneuvers that include backward motion}

During FY11, our trajectory generation algorithm was extended to include backward motion segments. During FY12, we refined the algorithm, integrated it with the existing autonomy system, and demonstrated backward manuevers in the field.

As with a human helmsman, we prefer to operate the vessel in forward motion. If all available forward trajectories are infeasible because they intersect a hazard to navitation, then we compute a trajectory that consists of a sternward motion segment followed by forward motion segment. The time at which the USV switches from sternward motion to forward motion is a degree of freedom in the optimizaiton problem.

Results of a field trail are shown in Figure 7. Green arrows indicate the direction of the bow of the USV, and the red dots represent the location of the USV at constant time intervals. The USV is traveling faster when red dots are further apart. The USV is in a small cove and begins the trial facing the shoreline. Because the USV is close to the shoreline, there is insufficient room to execute a forward turn, and the USV decides to move backwards. After the USV has moved backwards into the middle of the cove, it begins moving forward to exit the cove.

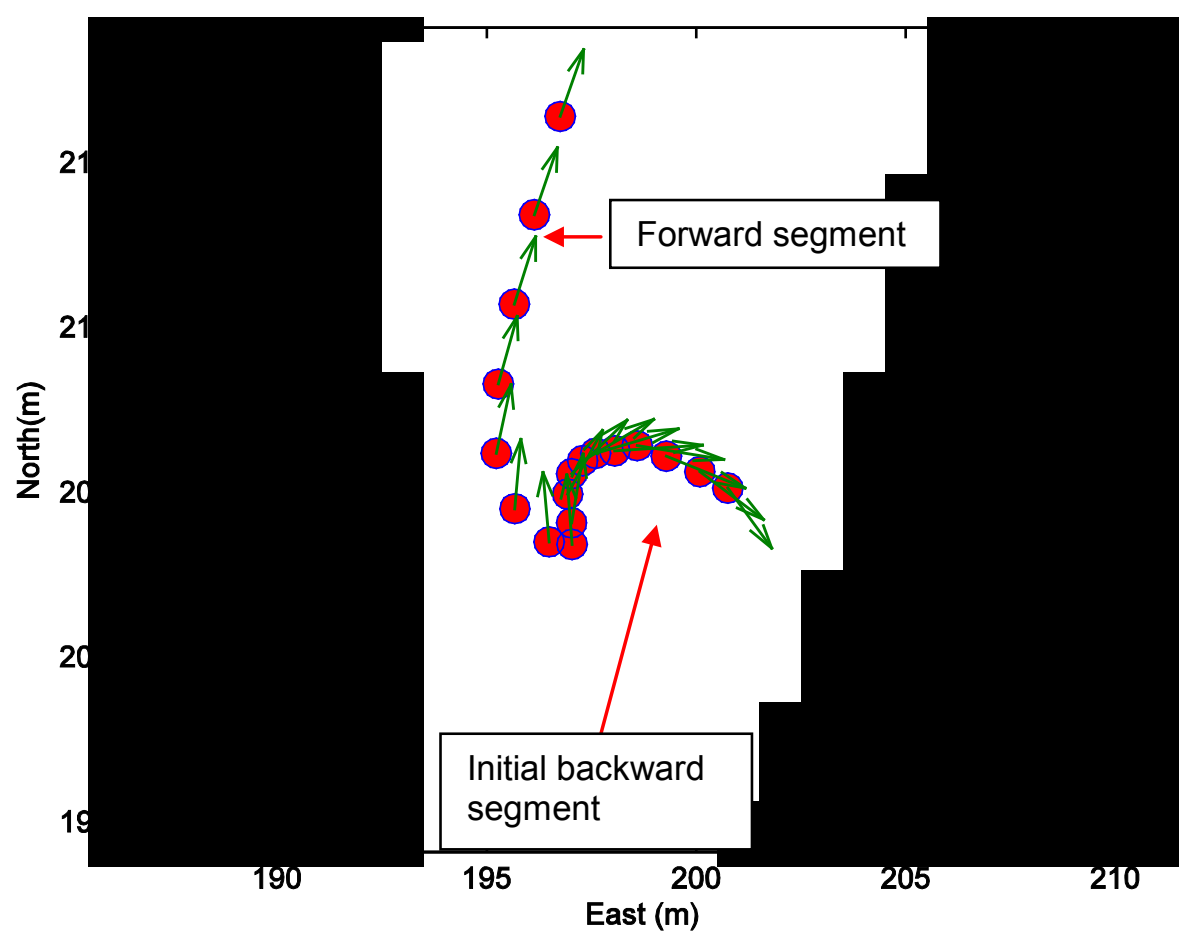

Figure 7. Trajectory of the USV that starts with backward motion and transitions to forward motion. Green arrows indicate direction of the bow.

\section{IMPACT/APPLICATIONS}

The principal result of this project will be a set of algorithms and best-practice tools for robust autonomous surface vehicle operations in dynamic and partially mapped riverine systems. 


\section{RELATED PROJECTS}

None

\section{PUBLICATIONS}

[1] AS Gadre, S Du, DJ Stilwell, 2012, A Topological map based approach to long range operation of an unmanned surface vehicle, Proc. American Control Conference, Montreal, Canada [peerreviewed, published].

[2] B Xu, DJ Stilwell, AJ Kurdila, 2012, Fast path re-planning based on fast marching and level sets, Journal of Intelligent and Robotic Systems [peer-reviewed, in press]

[3] AS Gadre, S Du, C Sonnenburg, D J Stilwell, CA Woolsey, 2012, Guidance and control of an unmanned surface vehicle exhibiting sternward motion, Proc. MTS/IEEE OCEANS, Hampton Roads, VA [peer-reviewed, accepted]

[4] C Sonnenburg, CA Woolsey, 2012, Modeling, identification, and control of an unmanned surface vehicle, Journal of Field Robotics [peer-reviewed, in review]

[5] P Thomasson and CA Woolsey, Vehicle motion in currents, IEEE Journal of Oceanic Engineering [peer-reviewed, in press]

[6] CA Woolsey, Vehicle Dynamics in Currents, VaCAS Technical Report No. VaCAS-2011-01.

[7] A Wolek, CA Woolsey, 2012, Disturbance rejection in Dubins path planning, Proc. American Control Conference, Montreal, Canada, June 2012 [peer-reviewed, published]. 